\title{
Does docosahexaenoic acid supplementation in term infants enhance neurocognitive functioning in infancy?
}

\author{
Alexandra E. Heaton ${ }^{1 *}$, Suzanne J. Meldrum ${ }^{1}$, Jonathan K. Foster ${ }^{1,2,3,4}$, Susan L. Prescott ${ }^{1,4}$ and \\ Karen Simmer ${ }^{1,4,5}$ \\ 1 School of Paediatrics and Child Health, University of Western Australia, Perth, WA, Australia \\ 2 School of Psychology and Speech Pathology, Curtin Health Innovation Research Institute, Curtin University, Perth, WA, Australia \\ ${ }^{3}$ Neurosciences Unit, Western Australia Department of Health, Perth, WA, Australia \\ ${ }^{4}$ Telethon Institute for Child Health Research, Perth, WA, Australia \\ ${ }^{5}$ Centre for Neonatal Research and Education, University of Western Australia, Perth, WA, Australia
}

Edited by:

Andrew Scholey, Swinburne University of Technology, Australia

Reviewed by:

Philippa Jackson, Northumbria

University, UK

James Kean, Swinburne University

of Technology, Australia

\section{${ }^{*}$ Correspondence:}

Alexandra E. Heaton, School of

Paediatrics and Child Health,

University of Western Australia,

M561, 35 Stirling Highway, Crawley,

Perth, WA 6009, Australia

e-mail: alexandra.heaton

@uwa.edu.au
The proposal that dietary docosahexaenoic acid (DHA) enhances neurocognitive functioning in term infants is controversial. Theoretical evidence, laboratory research and human epidemiological studies have convincingly demonstrated that DHA deficiency can negatively impact neurocognitive development. However, the results from randomized controlled trials (RCTs) of DHA supplementation in human term-born infants have been inconsistent. This article will (i) discuss the role of DHA in the human diet, (ii) explore the physiological mechanisms by which DHA plausibly influences neurocognitive capacity, and (iii) seek to characterize the optimal intake of DHA during infancy for neurocognitive functioning, based on existing research that has been undertaken in developed countries (specifically, within Australia). The major observational studies and RCTs that have examined dietary DHA in human infants and animals are presented, and we consider suggestions that DHA requirements vary across individuals according to genetic profile. It is important that the current evidence concerning DHA supplementation is carefully evaluated so that appropriate recommendations can be made and future directions of research can be strategically planned.

Keywords: neurocognitive, development, n-3 LC-PUFA, DHA, infant

\section{LC-PUFA IN THE CURRENT HUMAN DIET AND THE IMPORTANCE OF DHA FOR EARLY BRAIN DEVELOPMENT}

The omega-3 (n-3) long chain polyunsaturated fatty acid (LCPUFA), docosahexaenoic acid (DHA; 22:6 n-3), is involved in several critical brain functions (Bradbury, 2011). DHA accretes within the brain during gestation and the first year of life during the "brain growth spurt" (Innis, 2008). During this time, the developing brain is sensitive to extreme variations in the supply of DHA (Karr et al., 2011). DHA accretion in the fetal brain can be influenced by maternal diet, DHA stores, placental transport, and genetic polymorphisms (McCann and Ames, 2010). Dietary DHA is obtained during the postnatal period via breast milk or infant formula. The concentration of DHA within breast milk can vary depending on maternal DHA stores and diet (Innis, 2008). The average DHA intake of Australian women during pregnancy and lactation is below global recommendations; this is likely to impact the provision of DHA to the offspring (Bourre, 2007; Meyer, 2011).

Formula fed infants in many countries, including Australia, may also be at risk of receiving insufficient dietary DHA, since the inclusion of pre-formed $n-3$ and $n-6$ LC-PUFAs (including DHA) in formula is not mandatory. It is argued that infants are capable of synthesizing $n$ - 3 and $n$ - 6 LC-PUFAs endogenously from their shorter chain precursors (Guesnet and Alessandri,
2011). However, there is considerable debate around human capacity and ability to synthesize DHA. Research has found single nucleotide polymorphisms (SNPs) in the fatty acid desaturase genes (FADS1 and FADS2) modulate individual capacity for LC-PUFA synthesis (Glaser et al., 2011). Subsequently, it is now recognized that dietary requirements for DHA and other LC-PUFAs may vary across the population and are somewhat dependent on individual genetic profile (Koletzko et al., 2008). The need for LC-PUFA supplementation in term infants therefore remains unknown. This article summarizes the major animal studies and clinical trials pertaining to fatty acid supplementation during infancy, and evaluates the current level of evidence for LC-PUFA supplementation in term infants.

The $n-3$ and $n-6$ families are distinct groups of PUFAs important for human health, growth, and development. All PUFAs within the $n$ - 3 family are derived from alpha linolenic acid ( $\alpha$-LA; 18:3 n-3), while all $n-6$ PUFAs are derived from linoleic acid (LA; 18:2 n-6). (Figure 1) The (short chain) parent molecules of the $n-3$ and $n-6$ families, $\alpha-$ LA and LA, are described as "essential" fatty acids, since humans and other mammals cannot synthesize them endogenously (Kris-Etherton et al., 2000). The three most biologically active members of these families are the LC-PUFAs: DHA, eicosapentaenoic acid (EPA; 20:5 n-3) and arachidonic acid (AA; 20:4 n-6). These three fatty acids all carry out separate, 
complex functional roles in the body (McNamara and Carlson, 2006).

For Western nations, low dietary intake of EPA and DHA is a concern as these substances are not widely available in contemporary diets (Calder, 2012). There are few plant sources of DHA and EPA, and they are found almost exclusively in oily, cold water fish, fish oil supplements, breast milk, and supplemented infant formula. $\alpha-$ LA is available in oils such as canola and soybean, as well as in walnuts and flaxseed (Table 1). Converting $\alpha$-LA into EPA and DHA is a variable and inefficient process; stable-isotope tracer studies have shown that dietary $\alpha$-LA accounts for between 0.2 and $8 \%$ of EPA and $<0.05$ and $4 \%$ of DHA (Burdge and Calder, 2005; Plourde and Cunnane, 2007). Similarly, less than $0.1 \%$ of LA is converted into AA. Furthermore, conversion levels vary according to the intake of other fatty acids and the ratio of n-6: $n$-3 PUFAs consumed in the diet (Bokor et al., 2010). n-6 PUFA intakes in Western diets are typically high, supplying $\sim 16$ times more $n$-6 PUFA (including AA) than $n$-3 PUFA due to high intakes of beef, pork, poultry, wheat germ, and various cooking oils (Simopoulos, 2001b). In contrast, the diets of our paleolithic ancestors are thought to have contained roughly equal ratios of n-3: n-6 (Simopoulos, 2001a). Subsequently, there has been some debate as to whether modern diets contain sufficient quantities of $n$-3 fatty acids (in particular the $n$-3 LC-PUFAs, DHA and EPA) to support optimum health across the lifespan, especially during pregnancy and lactation (Eaton, 2000). It is possible that typical current levels of DHA intake are sufficient to achieve optimal neurocognitive functioning in childhood. This is the focus of the current review.

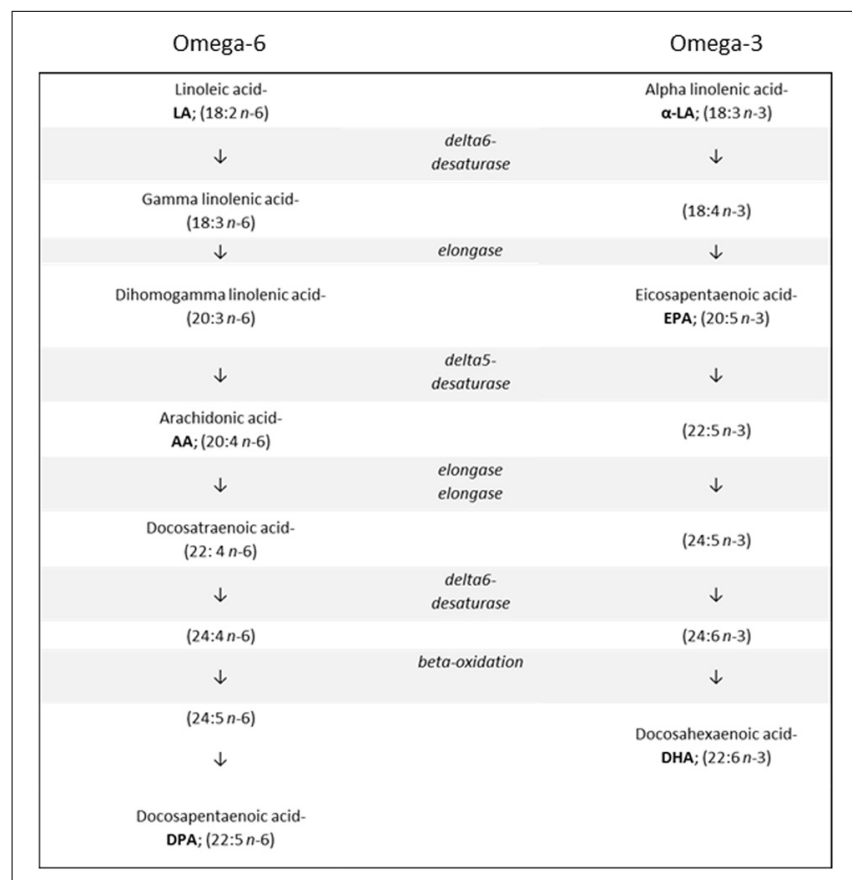

FIGURE 1 | The metabolic pathways involved in synthesizing $n-6$ and $n-3$ long chain polyunsaturated fatty acids from their respective shorter chain precursors.

\section{DHA WITHIN THE BRAIN AFFECTS NEURONAL DEVELOPMENT}

There have been several lines of evidence that suggest that LC-PUFAs (particularly DHA) are important for the function of the CNS at the cellular and neurobiological level. The concentration of DHA and other LC-PUFAs within the brain can alter the neuronal membrane fluidity and physical structure of neurons (Youdim et al., 2000). n-3 and n-6 LC-PUFAs are also involved in the production and activity of several neurotransmitters such as dopamine and serotonin (Zimmer et al., 2002; Aid et al., 2005; Chalon, 2006), affecting synaptic transmission and substrate binding to membrane receptors (Horrocks and Farooqui, 2004). Furthermore, DHA has been shown to affect neural functioning via its influence on gene expression in mammalian brain tissue (de Urquiza et al., 2000; Kitajka et al., 2004). The process of neurite outgrowth in hippocampal neurons is enhanced by DHA, which may in turn promote learning (Calderon and Kim, 2004) as the hippocampus is a critical brain region for memory formation (Rolls, 2008; Berger et al., 2012). DHA may also improve learning and memory through its role in the development of pre- and post-synaptic proteins which enable synaptic transmission and long-term potentiation (Cao et al., 2009). It is apparent that DHA plays numerous important biophysical roles in brain structure and function, and has the potential to influence neurocognitive development and subsequent performance (McNamara and Carlson, 2006; Parletta et al., 2013).

During the last trimester of gestation and for the first 18 months after birth, AA, and DHA are deposited within the cerebral cortex at a rapid rate (Martinez et al., 1974; Clandinin et al., 1980). As noted above, this stage of human development is known as the brain growth spurt (Martinez and Mougan, 1998), when neuronal development is particularly vulnerable to nutritional insufficiencies (Nyaradi et al., 2013). Further evidence from studies on young non-human primates has revealed that once brain DHA depletion has occurred it is physiologically difficult to reverse (Ikemoto et al., 2001).

Table 1 | Common dietary sources of $n-3$ and $n-6$ : short chain essential fatty acids ( $\alpha$-LA and LA) and long chain polyunsaturated fatty acids (DHA and AA) (Howe et al., 2006; Russo, 2009).

\begin{tabular}{|c|c|c|c|c|}
\hline & \multicolumn{2}{|r|}{ Omega-3 PUFA } & \multicolumn{2}{|r|}{ Omega-6 PUFA } \\
\hline $\begin{array}{l}\text { Dietary } \\
\text { sources: } \\
\text { EFA }\end{array}$ & $\begin{array}{l}\alpha- \\
L A\end{array}$ & $\begin{array}{l}\text { Vegetable oils: } \\
\text { linseed and canola } \\
\text { Flaxseed and } \\
\text { walnut } \\
\text { Fish: herring, } \\
\text { salmon, and tuna } \\
\text { Green leaves }\end{array}$ & LA & $\begin{array}{l}\text { Vegetable oils: } \\
\text { Corn, sunflower, and } \\
\text { safflower } \\
\text { Pork } \\
\text { Walnut, peanut, and } \\
\text { wheat } \\
\text { Fish: herring, salmon, } \\
\text { and tuna }\end{array}$ \\
\hline $\begin{array}{l}\text { Dietary } \\
\text { sources: } \\
\text { LC- } \\
\text { PUFA }\end{array}$ & $\begin{array}{l}\text { DHA } \\
\& \\
\text { EPA }\end{array}$ & $\begin{array}{l}\text { Fish: herring, } \\
\text { salmon, trout, tuna, } \\
\text { and fish oil } \\
\text { supplements } \\
\text { Breast milk }\end{array}$ & AA & $\begin{array}{l}\text { Beef, pork, and poultry } \\
\text { Whole-grain wheat }\end{array}$ \\
\hline
\end{tabular}




\section{DIETARY RECOMMENDATIONS FOR DHA DURING PREGNANCY AND THE NEONATAL PERIOD}

Considering the rapid accretion of DHA into the brain during the last trimester of pregnancy and into the first year of life, it is important to consider whether optimal DHA intake is occurring during this period. Numerous expert and government authorities worldwide agree that dietary DHA requirements are increased during pregnancy and lactation when a minimum of $200 \mathrm{mg}$ of DHA per day is recommended (Van Elswyk and Kuratko, 2009). This dose can be achieved by eating 1-2 portions of fish per week or taking fish oil supplements (Koletzko et al., 2008). Recent figures indicate that $91 \%$ of Australian women are failing to meet DHA recommendations during pregnancy and lactation (Cosatto et al., 2010), with similar trends noted in many other Western countries (Meyer, 2011). In Australia, the median daily intake of DHA during pregnancy is $\sim 96 \mathrm{mg}$ per day, ranging from 8 to $632 \mathrm{mg}$ per day across individuals (Cosatto et al., 2010). Since the dietary intake and maternal stores of DHA during pregnancy are known to be key determinants of infant blood DHA concentrations at birth (Bourre, 2007), low DHA consumption by women eating Western diets has prompted some concern for the neurological and neurocognitive development of their offspring (Rogers et al., 2013).

With respect to intake of DHA via breastfeeding, findings from the 2010 Australian National Infant Feeding Survey have revealed that while around $96 \%$ of Australian women initiate breastfeeding after birth, there is a rapid decline in breastfeeding rates during the weeks and months following birth (AIHW, 2011; Burns et al., 2012). Despite international recommendations for exclusive breastfeeding for the first 6 months postnatally (Kramer and Kakuma, 2001), in Australia an average of only $56 \%$ of women breastfeed for this recommended amount of time (AIHW, 2011).

Moreover, the concentration of DHA within women's breast milk appear to be decreasing over time (Makrides et al., 1995). A comprehensive analysis of human breast milk LC-PUFA compositions have revealed the current worldwide average DHA concentration is approximately $0.32 \%$ of total fatty acids (TFA) (Brenna et al., 2007). This corresponds to $\sim 60 \mathrm{mg}$ of DHA per day for the first 6 months postnatally, assuming an average breast milk intake of $750 \mathrm{~mL}$ per day (Cunnane et al., 2000). Analysis of Australian breast milk concentrations in 1981 and 1993 found that the amount of DHA decreased by $27 \%$ over this time period while concentrations of AA remained the same (Makrides et al., 1995). A similar decline in human milk DHA has been reported in a Canadian population (Innis, 2003). The decline in breast milk DHA may plausibly be explained by dietary shifts over time, the use of different FA analytical techniques (Makrides et al., 1995) or through differences in maternal FADS genotype across studies (Xie and Innis, 2008; Moltó-Puigmartí et al., 2010)—an issue that will be discussed further below.

Formula-fed infants may also be at risk of sub-optimal DHA supply during this period. DHA brain content has been analyzed in autopsy studies of human infants conducted in Australia (Makrides et al., 1994) and the United Kingdom (Farquharson et al., 1995). Both studies found that the brain tissue of breastfed infants contained higher concentrations of DHA compared to their standard formula-fed counterparts. These findings are consistent with animal studies, where dietary restriction of $n-3$ PUFA decreased the amount of DHA within the brain (Diau et al., 2005; Brenna, 2011; Luchtman and Song, 2013). One of the compelling arguments for including DHA and other LC-PUFAs in infant formula is to render its composition more similar to breast milk, which is commonly cited as the "gold standard" for infant nutrition (Burns et al., 2012). DHA enriched formula can enable formula-fed infants to attain DHA levels that are equivalent to their human milk receiving counterparts (Cunnane et al., 2000). However, clear functional benefits to infant development need to be demonstrated before DHA enriched formula can be unequivocally recommended.

\section{THE FUNCTIONAL EFFECTS OF DHA ON NEUROCOGNITION: EVIDENCE FROM STUDIES OF DEFICIENCY IN ANIMALS}

The evidence that DHA deficiency is detrimental to neurocognitive development is well established in animal models. The functional consequences of lower DHA concentrations within the CNS in baboons include visual (Neuringer et al., 1986) and motor deficits (Champoux et al., 2002). Studies have found that $n-3$ PUFA deficient rodents exhibit poorer performance in the Morris water maze test compared to their $n-3$ PUFA-sufficient counterparts (Sheaff et al., 1999; Moriguchi et al., 2000; Lim et al., 2005). DHA deficient mice exhibit a range of neurocognitive impairments, including problems with learning and memory (Catalan et al., 2002) and can have a heightened stress response (Fedorova and Salem, 2006). Detailed reviews in this area have been conducted by Davis-Bruno and Tassinari (2011) and Luchtman and Song (2013).

Animal studies allow more flexibility with respect to study design and potentially offer greater insight into the neurological mechanisms influenced by DHA deficiency in human infants (Romijn et al., 1991). However, there are limitations in the extrapolation of findings obtained in animal studies to the study of nutrition in humans. Research undertaken in non-human primates offers certain advantages over rodent studies in terms of transferability to humans, related to similarities in relative brain size, retinal microarchitecture and other anatomical, physiological and genealogical homologies (Brenna, 2011). However, human neurocognitive functioning is more complex and relies to a greater degree on higher cognitive capacities such as language and executive functioning (Luchtman and Song, 2013). A degree of caution should be applied when generalizing findings from animals to humans (Innis, 2007). Nonetheless, there is a strong and consistent body of evidence obtained from animal studies linking $n$-3 LC-PUFA deficiency to impaired neurocognitive functions. These links warrant further investigation through clinical research in humans.

\section{MATERNAL DIETARY DHA INTAKE AND SUPPLEMENTATION}

Epidemiological studies of maternal DHA intake provide insight into the potential value of DHA on neurocognitive outcomes. A very large observational study $(n=11,875)$ in pregnancy found a significant association between low maternal seafood consumption $(<340 \mathrm{~g}$ per week) and suboptimal neurocognitive outcomes in childhood (Hibbeln et al., 2007). Children aged 
6 months to 8 years whose mothers consumed low seafood diets during pregnancy had lower verbal IQ, displayed less prosocial behavior (defined as voluntary behavior intended to benefit another) and had poorer social and communication skills compared to those whose mothers consumed high seafood diets (Hibbeln et al., 2007). Furthermore, in a study of Canadian Inuit people (who typically consume a DHA-rich diet) DHA concentrations in umbilical cord plasma were positively associated with longer gestation, better visual acuity, higher scores of novelty preference on the Fagan test at 6 months and higher cognitive scores on the BSID-II of mental and psychomotor performance at 11 months (Jacobson et al., 2008). Most published observational epidemiological studies have recognized a positive association between maternal intake of $n$-3 LC-PUFA rich foods during pregnancy and neurocognitive development of offspring (Oken et al., 2005, 2008; Hibbeln et al., 2007; Mendez et al., 2009; Boucher et al., 2011). The observational study by Gale et al. (2008), however, detected no association between the frequency with which mothers ate fish in pregnancy and full-scale or performance IQ of their offspring at 9 years of age. Nevertheless, these researchers did find that children whose mothers had eaten oily fish had higher verbal IQ and a reduced risk of hyperactivity compared to those children whose mothers did not eat oily fish, after adjustment for potential confounding factors. However, the findings of these studies are somewhat weakened due to potentially confounding variables, including social and economic differences that may independently affect neurodevelopmental outcomes in childhood (Drane and Logemann, 2000; Boyd et al., 2013).

It is well established that maternal fish oil supplementation during pregnancy substantially increases fetal DHA concentration at the time of birth (Larqué et al., 2012). Furthermore, two randomized controlled trials (RCTs) have shown that DHA supplementation during pregnancy offers significant benefit to infant neurocognitive development (Judge et al., 2007; Dunstan et al., 2008). However, the RCTs in this area are not easily comparable and positive effects have not been identified in all studies (Lo et al., 2012). One long term follow-up found that maternal supplementation enhanced neurocognitive outcomes up to 4 years later (Helland et al., 2003) but the effect did not persist after 7 years (Helland et al., 2008). A relatively large RCT $(n=249)$ from Bangladesh found that maternal DHA supplementation from 25 weeks gestation until delivery had no effect on infant BSID-II mental and psychomotor performance outcomes at 10 months (Tofail et al., 2006). Such findings may not be directly comparable to an Australian population since maternal nutrition and anthropometric status in developing countries are often low (Karim and Mascie-Taylor, 1997; Dhar et al., 2003). It is also possible that the control oil used in this study (which contained $\alpha$-LA: $2700 \mathrm{mg}$ and LA: $2250 \mathrm{mg}$ per day) may have inadvertently promoted infant neurocognitive status, thereby attenuating any treatment effect from the intervention (Tofail et al., 2006).

A meta-analysis and systematic review of maternal $n$-3 LCPUFA supplementation undertaken by Gould et al. (2013) highlighted numerous potential areas of bias in the current literature and remarked on the relatively poor quality of most RCTs in this field. Of major concern was the consideration that publications seldom reported the randomization process and/or method(s) used to conceal treatment allocation from participants. According to this review, the only RCT of maternal DHA supplementation and infant neurocognitive outcomes that was considered to be genuinely free from bias was conducted in Australia by Makrides et al. (2011a). This RCT found no significant association between moderate DHA supplementation ( $800 \mathrm{mg}$ per day) during pregnancy and BSID-II scores of language or cognitive development at $2 \frac{1}{2}$ years $(n=2399)$. However, this RCT revealed that children in the treatment group manifested significantly lower incidence of cognitive delay compared to their un-supplemented counterparts.

In summary, RCTs and epidemiological studies evaluating the potential neurocognitive impact of maternal DHA supplementation during pregnancy have revealed somewhat heterogeneous results in healthy term infants. Consequently, it may be premature to make unequivocal recommendations about any neurocognitive benefits of DHA supplementation in healthy term infants based on the currently available research findings.

\section{CORRELATIONS BETWEEN INFANT NEUROCOGNITION AND BREASTFEEDING}

Over the years, many prospective observational studies have indicated that breastfed infants have a significant neurocognitive advantage over their formula fed counterparts (Anderson et al., 1999; Agostoni et al., 2001; Oddy et al., 2003, 2011; Kramer et al., 2008). It has been theorized that this is due to the higher presence of DHA in breast milk, relative to formula milks. Some studies have found positive associations between DHA concentrations within breast milk and/or infant blood levels and better outcomes of visual acuity (Innis et al., 2001; Jørgensen et al., 2001). However, it is likely that breastfeeding enhances infant development due to a number of inter-related factors as reviewed in Jain et al. (2002). Specifically, observational studies are potentially confounded by the heterogeneous composition of breast milk (both within and between lactating individuals), environmental factors such as maternal/infant bonding and other influences (Jain et al., 2002). One particularly significant potentially confounding factor is social economic status (SES), which is positively associated with both maternal and infant IQ, along with the decision to breastfeed (Der et al., 2006; de Jager et al., 2013). Furthermore, the breastfeeding act itself may be indicative of maternal attentiveness and nurturing which may independently foster long term positive effects on infant neurocognitive outcomes (Morley et al., 1988). Despite appropriate statistical techniques used to try to control for the influence of confounders, observational studies can be subject to systematic bias and results should therefore be interpreted with some caution.

A study by Caspi et al. (2007) tested the association between breastfeeding and child IQ with respect to FADS2 genetic profile, specifically in terms of the SNP rs174575. Breastfed infants who were rs174575 C-dominant carriers achieved higher scores on standardized IQ tests compared to the C-carriers who were not breastfed. Meanwhile, children homozygous for the minor allele (GG genotype) were found to have similar IQs, irrespective of feeding method. These findings remained statistically significant after accounting for potential confounding variables including intrauterine growth, family social economic status, and maternal cognitive ability. While potentially important in terms of the 
possible interaction between breastfeeding and the genetic status of the infant, these findings have yet to be replicated by other research studies.

\section{CORRELATIONS BETWEEN INFANT NEUROCOGNITION AND DHA STATUS}

Many trials have found that higher plasma or RBC DHA concentrations (often as a result of LC-PUFA supplementation) are positively correlated with infant neurocognitive outcomes (Agostoni et al., 1995, 1997; Gibson et al., 1997; Birch et al., 2000; Innis et al., 2001; Helland et al., 2003; Innis, 2003; Jensen et al., 2005; Drover et al., 2011). Some studies, on the other hand, have found no significant relationships (Lucas et al., 1999; Makrides et al., 2000; Auestad et al., 2001), while conversely two studies have found that higher infant DHA blood concentration has a negative neurocognitive effect (Scott et al., 1998; Lauritzen et al., 2005). It should be cautioned that associations between DHA status and infant neurocognitive status do not necessarily demonstrate causality, nor do they demonstrate the effectiveness of the intervention alone-as this may be confounded by other nutrients (Innis, 2003).

\section{RCTs OF LC-PUFA SUPPLEMENTATION IN TERM AND PRETERM POPULATIONS}

In order to confirm whether dietary LC-PUFA is responsible for the enhanced neurocognitive outcomes associated with breastfeeding and higher DHA status, RCTs of LC-PUFA supplementation are necessary. Several of these trials have been conducted, usually in formula-fed infants. The most common methodology involves comparing the neurodevelopmental outcomes of infants randomized to receive infant formula with DHA (either alone or in combination with AA and/or other PUFAs) or placebo (unsupplemented formula). The majority of trials in healthy term infants have shown little or no consistent, beneficial effects on neurocognitive outcomes as a result of dietary LC-PUFA supplementation. However, infant LC-PUFA supplementation has resulted in no negative effects on growth, development or morbidity (Koletzko et al., 2005). There is, therefore, currently no compelling argument either for or against LC-PUFA supplementation in term infants with respect to neurocognitive outcomes. This conclusion has been re-iterated in three consecutive versions of the Cochrane review (Simmer, 2001; Simmer et al., 2008, 2011) that have evaluated 9, 14, and 15 relevant RCTs, respectively. Interestingly, in the authors' conclusions for both the (2008) and (2011) Cochrane reviews, Simmer et al. refer to the positive results found by the Dallas group (Birch et al., 2005) and state that these results need to be replicated in other settings. These authors also propose that future RCTs should explore the use of DHA derived from single cell microalgae and supply higher doses of DHA, in line with typical human milk (DHA 0.32\%) concentrations throughout the world.

Hoffman et al. (2009) reviewed 20 RCTs within this field including several studies not included in the Simmer et al. (2008) Cochrane review and elaborated on some methodological factors including dosage, source, and duration of supplementation. Hoffman et al. (2009) concluded that trials which supplied term infants with DHA in concentrations greater than $0.3 \%$ TFA (in addition to AA >0.3\% TFA) were more likely to identify a significantly positive effect on neurocognitive and visual outcomes. In another meta-analysis utilizing individual patient data (IPD) with a considerable sample size $(n=870)$, Beyerlein et al. (2010) combined the raw scores from four methodologically similar RCTs (Lucas et al., 1999; Fewtrell et al., 2002, 2004; Bouwstra et al., 2005) which each assessed BSID-II outcomes at 18 months. The analysis concluded that LC-PUFA supplemented formula conveys no significant benefit on neurodevelopment at 18 months, as assessed using the BSID-II. However, this meta-analysis was unable to access IPD from all relevant trials (Birch et al., 2000; Clandinin et al., 2005).

Evidence that infant DHA supplementation conveys significant benefit on visual acuity is derived from a systematic review of 12 clinical studies from the Harvard School of Public Health (SanGiovanni et al., 2000). SanGiovanni et al. (2000) incorporated the results from both randomized and non-randomized studies of DHA supplemented formula and concluded that increased dietary DHA improved visual acuity in term infants at two and four months of age. It should be cautioned that analyses that combine findings from both randomized and nonrandomized trials have a higher risk of incorporating selection bias in the recruitment for the trial (Szajewska, 2011). More recent reviews in this field suggest that more research is required before definitive recommendations can be made concerning whether term infants would benefit from $n$-3 LC-PUFA supplemented formula (Agostoni, 2008; Benton, 2008; Belkind-Gerson et al., 2008; Makrides et al., 2011b; Campoy et al., 2012).

The majority of RCTs of infant DHA supplementation (as described above) use infant formula and are constrained by the consideration that their study samples have chosen not to breastfeed, thereby reducing external validity of the findings (Gibson and Makrides, 1998; Smithers et al., 2008a). There have been a small number of studies which have supplemented infants with DHA directly, thereby bypassing the need to employ formulabased supplementation. To the best of our knowledge, only one such direct supplementation RCT has addressed the effect of DHA on infant neurocognitive functioning (Meldrum et al., 2012). In this recent double-blinded, placebo-controlled trial conducted in Australia (Meldrum et al., 2012), healthy term infants $(n=287)$ were randomized to either very high dose fish oil (incorporating $>250 \mathrm{mg}$ DHA plus $60 \mathrm{mg}$ EPA) or placebo (olive oil) per day from birth to 6 months. The study determined that while infants within the fish oil group had significantly higher DHA concentrations in erythrocyte and plasma phospholipids at 6 months of age relative to the placebo group, there was no significant difference between standard or composite scores of the BSID-III (third edition) at 18 months or on outcomes from the Child Behavior Checklist. In a subtest which explored the development of infant communication skills $(n=185)$, the study found that scores for later developing gestures and total number of gestures were significantly higher in the fish oil group compared to the placebo group at both 12 and 18 months. This finding is interesting since gestural skills in infancy are associated with visual recognition memory, deferred imitation and turn-taking skills (Heimann et al., 2006). Furthermore, these skills are understood to predict language and communicative ability in later life 
(Acredolo and Goodwyn, 1988). Direct supplementation of the oil emulsion allowed participation of breast- and/or formula-fed infants alike. However, a potential criticism of this study is that the odor of the fish oil may not have been adequately masked, and therefore parents were frequently able determine which treatment their child was receiving. This, in turn, may have affected parents' ratings of their child's gestural abilities.

While the focus of the current paper is on term infant neurocognitive response to DHA supplementation, valuable information can be gleaned from investigation into the preterm population. Preterm infants are especially vulnerable to DHA deficiency as they have not had access to maternal lipid stores for the normal period of gestation (Haggarty, 2002). Similar to full term infants, preterm infants fed formula milk without DHA have lower DHA status compared to those fed human milk (Carlson et al., 1986) or LC-PUFA supplemented formula (Koletzko et al., 1989; Lapillonne et al., 2000). It has been identified that children born preterm have higher rates of learning disabilities, language impairment, attention deficits, hyperactivity, and reduced cognitive test scores compared to (gender- and age-matched) children born at term (Bhutta et al., 2002; Perricone and Morales, 2011). Although there are many factors associated with preterm delivery, it is possible that lower DHA status during the critical period of brain growth may contribute toward impaired neurocognitive development (McNamara and Carlson, 2006).

The DINO (DHA infant neurodevelopmental outcomes) double-blind RCT provided supplementation to lactating mothers $(n=657)$ in order to increase breast milk DHA (Makrides et al., 2009). Lactating women were either supplied six $500 \mathrm{mg}$ DHA-rich tuna oil capsules per day or placebo soy oil capsules. Mothers were encouraged to breastfeed; however, if the mother chose not to provide breast-milk or if additional milk was required, infant formula was provided. The DHA concentrations of the formula matched the typical milk DHA concentrations of the two groups. The study found that preterm infants in the DHA group had better visual development (as determined through sweep VEP acuity) at 4 months corrected age [i.e., chronological age corrected for the degree of prematurity; (Smithers et al., 2008b)]. A higher mean mental development index of children in the DHA supplemented group (as assessed using the BSID-II) was found. However, after adjusting for confounding factors this benefit was not statistically significant $(p=0.2)$. Yet the number of children in the DHA group with low cognitive scores (indicative of mildly delayed development) was significantly smaller in the treated group compared with the control group. In pre-planned secondary analyses, the DINO study found DHA supplementation had a significantly positive effect on cognitive outcomes in girls compared to boys. The reason for differences in response to DHA as a function of gender remains unclear but may be related to the higher rate of LC-PUFA synthesis that has been identified in females (Burdge and Nagura, 2002). The authors proposed that the dose of DHA chosen for this study may not have been sufficient to elicit equivalent neurocognitive benefits in males and they considered whether enhancing DHA concentrations may evoke neurocognitive advantages (Makrides et al., 2009). Furthermore, the authors concluded that the DHA concentration in standard human breast milk of Australian women is sub-optimal for the visual development of preterm infants (Smithers et al., 2008b).

There have been numerous LC-PUFA supplementation trials in preterm infants which have reported greater visual acuity following enhanced dietary DHA relative to placebo (Birch et al., 1992; Carlson et al., 1993; Smithers et al., 2008b). Similarly, numerous RCTs in preterm populations have found that DHA supplementation positively affects neurocognitive outcomes including language comprehension (O'Connor et al., 2001), memory (Henriksen et al., 2008) and mental and psychomotor development (Clandinin et al., 2005). However, the review by Qawasmi et al. (2012) points out that there are also many RCTs which have consistently shown no neurocognitive effect, both in preterm and term infant populations. Similarly, Schulzke et al. (2011) concluded that there is insufficient evidence to recommend DHA supplementation with respect to routine neonatal care in preterm infants. The most recent Cochrane review of LC-PUFA supplementation of preterm formula concludes that there are no clear long-term benefits on visual or intellectual development after pooling data across studies of preterm infants (Schulzke et al., 2011). Finally, two recently published reviews reflect uncertainty as to whether preterm infants should be supplemented with dietary DHA with respect to potential long term neurocognitive or developmental benefits (Molloy et al., 2012; Lapillonne et al., 2013). Further investigation is clearly warranted concerning the role of DHA supplementation in modulating optimal neurocognitive outcomes in preterm infant populations.

\section{GENETIC FACTORS MODULATING INDIVIDUAL DIETARY REOUIREMENTS FOR $n-3$ LC-PUFAs}

A relatively new area of investigation concerns how genetic differences may modulate individual LC-PUFA requirements. Such research has focused on the genes FADS1 and FADS2. These genes are known to act upon the enzymes delta-5 desaturase (D5D) and delta-6 desaturase (D6D) and influence the efficiency with which shorter chain $n-3$ and n-6 PUFAs are converted into LCPUFA products (Nakamura and Nara, 2004; Schaeffer et al., 2006; Rzehak et al., 2009; Bokor et al., 2010; Glaser et al., 2011). The D5D and D6D enzymes are present in the human liver from early gestation (Innis, 2005). The fetus is capable of synthesizing $n$ 3 LC-PUFAs from shorter chain $n$-3 precursors from 26 weeks gestation (Uauy et al., 2000).

SNPs within FADS1 and FADS2 have been associated with the ratio of desaturation precursors (i.e., $\alpha$-LA, LA, eicosadienoic acid (EDA; 20:2 n-6) and dihomogamma linolenic acid (DGLA; 20:3 $n-6)$ to desaturation products, including the LC-PUFAs (EPA, DPA, and AA) (Schaeffer et al., 2006; Gillingham et al., 2013). In a very large German study conducted in an adult population, the authors found that up to $28 \%$ of AA variability was associated with 11 common SNPs (and 5 SNPs of reconstructed haplotypes) from the FADS1 and FADS2 gene clusters (Schaeffer et al., 2006). Yet, the FADS polymorphisms tested by Schaeffer et al. (2006) could only explain $\sim 7 \%$ of EPA and $3 \%$ of DHA levels. Few subsequent studies have been able to identify a significant association between FADS polymorphisms and DHA concentrations in human populations (Koletzko et al., 2011; Lattka et al., 2013). 
However, Koletzko et al. (2011) identified significant associations between fetal and maternal FADS genotypes and DHA concentrations in fetal circulation, irrespective of maternal diet. While it currently appears that DHA concentrations are primarily modulated though dietary supply, several FADS genetic polymorphisms are still under investigation internationally (Glaser et al., 2011; Gillingham et al., 2013) and are currently being considered in our laboratory.

\section{INTERPRETING CURRENT RESEARCH FINDINGS}

Inconsistent findings within this literature have been the subject of much consideration. suggestions as to why discrepancies may have occurred are outlined in the review published by Meldrum et al. (2011). Previous studies were identified as having considerable variability in: (i) inadequate sample sizes, (ii) doses of DHA utilized, (iii) source of DHA used (i.e., algal or fish sources), (iv) age at which supplementation was initiated, (v) duration of supplementation, (vi) type of neurocognitive/developmental assessments used to evaluate neurocognitive functioning, and (vii) variability in participant compliance across studies. It was also speculated in this review that genetic polymorphisms might represent a potentially relevant factor affecting the outcomes of these RCTs. It is now recognized that dietary requirements for DHA and other LC-PUFAs may be somewhat heterogeneous across individuals; for example, being somewhat dependent on an individual's genetic profile (Koletzko et al., 2011).

In addition to FADS genetic considerations, the lack of consistency across RCTs of DHA supplementation may also be due, at least in part, to gender based differences in LC-PUFA metabolism from shorter chain precursors (Guesnet and Alessandri, 2011). It is known that the capacity to convert $\alpha$-LA into $n$-3 LC-PUFAs including DHA is significantly greater in females than in males (Burdge, 2004), resulting in higher DHA circulating plasma concentration in females (Giltay et al., 2004). This is thought to be due to the influence of estrogen and other hormones on the activity and expression of D5D and D6D in the liver (Extier et al., 2010; Decsi and Kennedy, 2011). Evidence from the Western Australian pregnancy cohort (Raine) study $(n=1038)$ has also found long term neurocognitive benefits from breastfeeding to be gender specific (Oddy et al., 2011). This study found that breastfeeding had a more pronounced neurocognitive benefit on male infants, as evident until 10 years of age (Oddy et al., 2011). A gender specific response to DHA enriched human breast milk was also observed by Makrides et al. (2009) in the aforementioned DINO study of preterm infants. Females manifest a greater capacity for LC-PUFA synthesis (Burdge and Nagura, 2002), such that males may have higher dietary DHA requirements during infancy (Makrides et al., 2009).

\section{CONCLUSIONS AND FUTURE DIRECTIONS}

DHA is known to play a critical role in the developing human brain and there is evidence of its neurobiological importance during infancy (McCann and Ames, 2005). DHA deficiencies in animals have proven to exert deleterious effects on a range of neurodevelopmental outcomes (McNamara and Carlson, 2006). High intake of oily fish during pregnancy appears to benefit children's neurocognitive development. Additionally, several studies have demonstrated positive associations between infant blood concentrations of DHA and neurocognitive status (Innis, 2003, 2007). Yet previous RCTs undertaken in this field provide conflicting evidence concerning the putative neurocognitive benefits of $n$-3 LC-PUFA supplementation in healthy full term infants. Despite the consideration that the majority of RCTs report little or no effect from supplementation (as cited in several Cochrane reviews and meta-analyses), many researchers suggest that further work should be undertaken in order to better define optimal DHA intakes before and during infancy.

It is possible that DHA deficiency during critical periods of brain growth and structural organization may render the brain vulnerable to neurological or neurodegenerative diseases later in life (Farquharson et al., 1995). The development of the brain's architecture prenatally and during infancy lays down the foundation on which the structure of the adult brain is based. It is therefore possible that early modification of LC-PUFA levels will have long-term structural and functional consequences which may be too long-term and/or subtle to detect in healthy infants and children (McNamara and Carlson, 2006). However, more noticeable effects may emerge in older individuals. In this context, the equivocal findings obtained in this field to date are heuristic, as they will stimulate further research which should more rigorously control for the potentially confounding variables that have been identified in this review. As proposed by Alderson and Roberts (2000), inconclusive results are potentially very informative in biomedical science as they stimulate further inquiry and ultimately improve health outcomes for future generations.

While RCTs are generally thought to provide the most robust indexes of causal mechanisms in human clinical research (Szajewska, 2011), the results from observational studies in humans and intervention studies in laboratory animals also deserve serious consideration. In future, larger and higher dose RCTs should be undertaken using more sensitive measures of infant and child neurocognitive capacity. A more careful approach to the design and analysis of observational epidemiological studies is also likely to yield tangible benefit (for example, through undertaking larger studies which are able to consider a wider range of potentially confound variables).

Debate about the usefulness of dietary DHA during infancy has been ongoing for over 30 years and a wealth of data have been collected by research groups around the world. It would be of far-reaching benefit for more international collaboration to be undertaken within this area of inquiry. Data access facilitated through computational platform/s that enable sharing of de-identified, IPD could provide researchers with the means to carry out statistically novel methods of data interpretation on a very large scale. Meta-analysis of IPD allows researchers to analyze the raw data of relevant original studies (using similar covariates) and thereby derive potentially more reliable conclusions (Stewart and Parmar, 1993). To the best of our knowledge, only one IPD meta-analysis on the neurocognitive effects of LC-PUFA supplementation during infancy has been conducted (Beyerlein et al., 2010). This meta-analysis was able to access the raw data from 4 out of the 6 relevant RCTs. The limitations imposed on this IPD meta-analysis by the non-availability of data from two relevant RCTs could 
be prevented in future if guidelines and policies are implemented within a collaborative international scientific framework that is more sensitive to ethico-legal and data-ownership issues.

Despite the absence of a scientific consensus with regard to putative benefits (as identified in this review), many manufacturers of infant formula include DHA and AA in certain formulations and market them as "superior products" which provide a distinct neurocognitive advantage (Simmer et al., 2011). This shaping of public opinion through retail is controversial, considering that there is little concrete scientific evidence to support these claims. Australia is one of the leading markets for $n-3$ products and supplements and, consequently, consumers are at increased risk of being misled by current marketing approaches (McManus et al., 2011). It is important for future research to address these claims definitively, so as to either avoid unnecessary supplementation of infants' diets (and the associated economic cost) or to ensure that infants are universally provided with adequate dietary DHA to prevent suboptimal neurocognitive development.

\section{REFERENCES}

Acredolo, L., and Goodwyn, S. (1988). Symbolic gesturing in normal infants. Child Dev. 59, 450-466. doi: 10.2307/1130324

Agostoni, C. (2008). Role of long-chain polyunsaturated fatty acids in the first year of life. J. Pediatr. Gastroenterol. Nutr. 47, S41-S44. doi: 10.1097/01.mpg.0000338811.52062.b2

Agostoni, C., Marangoni, F., Lammardo, A. M., Giovannini, M., Riva, E., and Galli, C. (2001). Breastfeeding duration, milk fat composition and developmental indices at 1 year of life among breastfed infants. Prostaglandins Leukot. Essent. Fatty Acids 64, 105-109. doi: 10.1054/plef.2001.0248

Agostoni, C., Trojan, S., Bellù, R., Riva, E., Bruzzese, M. G., and Giovannini, M. (1997). Developmental quotient at 24 months and fatty acid composition of diet in early infancy: a follow up study. Arch. Dis. Child. 76, 421-424. doi: 10.1136/adc.76.5.421

Agostoni, C., Trojan, S., Bellu, R., Riva, E., and Giovannini, M. (1995). Neurodevelopmental quotient of healthy term infants at 4 months and feeding practice: the role of long-chain polyunsaturated fatty acids. Pediatr. Res. 38, 262-266. doi: 10.1203/00006450-199508000-00021

Aid, S., Vancassel, S., Linard, A., Lavialle, M., and Guesnet, P. (2005). Dietary docosahexaenoic acid [22: $6(n-3)]$ as a phospholipid or a triglyceride enhances the potassium chloride-evoked release of acetylcholine in rat hippocampus. J. Nutr. 135, 1008-1013.

AIHW. (2011). "2010 Australian national infant feeding survey: indicator results," in Australian Institute of Health and Welfare. Cat. no. PHE 156., (Canberra).

Alderson, P., and Roberts, I. (2000). Should journals publish systematic reviews that find no evidence to guide practice? Examples from injury research. BMJ 320, 376-377. doi: 10.1136/bmj.320.7231.376

Anderson, J. W., Johnstone, B. M., and Remley, D. T. (1999). Breast-feeding and cognitive development: a meta-analysis. Am. J. Clin. Nutr. 70, 525-535.

Auestad, N., Halter, R., Hall, R. T., Blatter, M., Bogle, M. L., Burks, W., et al. (2001). Growth and development in term infants fed long-chain polyunsaturated fatty acids: a double-masked, randomized, parallel, prospective, multivariate study. Pediatrics 108, 372-381. doi: 10.1542/peds.108.2.372

Belkind-Gerson, J., Carreón-Rodríguez, A., Contreras-Ochoa, C. O., Estrada-Mondaca, S., and Parra-Cabrera, M. S. (2008). Fatty acids and neurodevelopment. J. Pediatr. Gastroenterol. Nutr. 47, 7-9. doi: 10.1097/MPG.0b013e3181818e3f

Benton, D. (2008). The influence of children's diet on their cognition and behavior. Eur. J. Nutr. 47, 25-37. doi: 10.1007/s00394-008-3003-x

Berger, T. W., Song, D., Chan, R. H. M., Shin, D., Marmarelis, V. Z., Hampson, R. E., et al. (2012). Role of the hippocampus in memory formation: restorative encoding memory integration neural device as a cognitive neural prosthesis. IEEE Pulse 3, 17-22. doi: 10.1109/MPUL.2012.2205775
Beyerlein, A., Hadders-Algra, M., Kennedy, K., Fewtrell, M., Singhal, A., Rosenfeld, E., et al. (2010). Infant formula supplementation with long-chain polyunsaturated fatty acids has no effect on bayley developmental scores at 18 months of age-IPD meta-analysis of 4 large clinical trials. J. Pediatr. Gastroenterol. Nutr. 50, 79-84. doi: 10.1097/MPG.0b013e3181acae7d

Bhutta, A. T., Cleves, M. A., Casey, P. H., Cradock, M. M., and Anand, K. S. (2002). Cognitive and behavioral outcomes of school-aged children who were born preterm: a meta-analysis. J. Am. Med. Assoc. 288, 728-737. doi: 10.1001/jama.288.6.728

Birch, D. G., Birch, E. E., Hoffman, D. R., and Uauy, R. D. (1992). Retinal development in very-low-birth-weight infants fed diets differing in omega-3 fatty acids. Invest. Ophthalmol. Vis. Sci. 33, 2365-2376.

Birch, E. E., Castañeda, Y. S., Wheaton, D. H., Birch, D. G., Uauy, R. D., and Hoffman, D. R. (2005). Visual maturation of term infants fed long-chain polyunsaturated fatty acid-supplemented or control formula for $12 \mathrm{mo}$. Am. J. Clin. Nutr. 81, 871-879.

Birch, E. E., Garfield, S., Hoffman, D. R., Uauy, R., and Birch, D. G. (2000). A randomized controlled trial of early dietary supply of long-chain polyunsaturated fatty acids and mental development in term infants. Dev. Med. Child Neurol. 42, 174-181. doi: 10.1017/S0012162200000311

Bokor, S., Dumont, J., Spinneker, A., Gonzalez-Gross, M., Nova, E., Widhalm, K., et al. (2010). Single nucleotide polymorphisms in the FADS gene cluster are associated with delta- 5 and delta- 6 desaturase activities estimated by serum fatty acid ratios. J. Lipid Res. 51, 2325-2333. doi: 10.1194/jlr.M006205

Boucher, O., Burden, M. J., Muckle, G., Saint-Amour, D., Ayotte, P., Dewailly, E., et al. (2011). Neurophysiologic and neurobehavioral evidence of beneficial effects of prenatal omega-3 fatty acid intake on memory function at school age. Am. J. Clin. Nutr. 93, 1025-1037. doi: 10.3945/ajcn.110.000323

Bourre, J.-M. (2007). Dietary omega-3 fatty acids for women. Biomed. Pharmacother. 61, 105-112. doi: 10.1016/j.biopha.2006.09.015

Bouwstra, H., Dijck-Brouwer, D. A. J., Boehm, G., Boersma, E. R., Muskiet, F. A. J., and Hadders-Algra, M. (2005). Long-chain polyunsaturated fatty acids and neurological developmental outcome at 18 months in healthy term infants. Acta Paediatr. 94, 26-32. doi: 10.1080/08035250410020190

Boyd, A., Golding, J., Macleod, J., Lawlor, D. A., Fraser, A., Henderson, J., et al. (2013). Cohort profile: the 'children of the 90s'-the index offspring of the Avon longitudinal study of parents and children. Int. J. Epidemiol. 42, 111-127. doi: 10.1093/ije/dys064

Bradbury, J. (2011). Docosahexaenoic acid (DHA): an ancient nutrient for the modern human brain. Nutrients 3, 529-554. doi: 10.3390/nu3050529

Brenna, J. T. (2011). Animal studies of the functional consequences of suboptimal polyunsaturated fatty acid status during pregnancy, lactation and early postnatal life. Matern. Child Nutr. 7, 59-79. doi: 10.1111/j.1740-8709.2011.00301.x

Brenna, J. T., Varamini, B., Jensen, R. G., Diersen-Schade, D. A., Boettcher, J. A., and Arterburn, L. M. (2007). Docosahexaenoic and arachidonic acid concentrations in human breast milk worldwide. Am. J. Clin. Nutr. 85, 1457-1464.

Burdge, G. C. (2004). alpha-Linolenic acid metabolism in men and women: nutritional and biological implications. Curr. Opin. Clin. Nutr. Metab. Care 7, 137-144. doi: 10.1097/00075197-200403000-00006

Burdge, G. C., and Calder, P. C. (2005). Conversion of alpha-linolenic acid to longer-chain polyunsaturated fatty acids in human adults. Reprod. Nutr. Dev. 45, 581-597. doi: 10.1051/rnd:2005047

Burdge, G. C., and Nagura, T. (2002). Conversion of a-linolenic acid to eicosapentaenoic, docosapentaenoic and docosahexaenoic acids in young women. $\mathrm{Br}$. J. Nutr. 88, 411-420. doi: 10.1079/BJN2002689

Burns, E., Schmied, V., Fenwick, J., and Sheehan, A. (2012). Liquid gold from the milk bar: constructions of breastmilk and breastfeeding women in the language and practices of midwives. Soc. Sci. Med. 75, 1737-1745. doi: 10.1016/j.socscimed.2012.07.035

Calder, P. C. (2012). Mechanisms of action of (n-3) fatty acids. J. Nutr. 142, 592S-599S. doi: 10.3945/jn.111.155259

Calderon, F., and Kim, H.-Y. (2004). Docosahexaenoic acid promotes neurite growth in hippocampal neurons. J. Neurochem. 90, 979-988. doi: 10.1111/j.1471-4159.2004.02520.x

Campoy, C., Escolano-Margarit, M. V., Anjos, T., Szajewska, H., and Uauy, R. (2012). Omega 3 fatty acids on child growth, visual acuity and neurodevelopment. Br. J. Nutr. 107(Suppl. 2), 85-106. doi: 10.1017/S0007114512001493

Cao, D., Kevala, K., Kim, J., Moon, H.-S., Jun, S. B., Lovinger, D., et al. (2009). Docosahexaenoic acid promotes hippocampal neuronal development 
and synaptic function. J. Neurochem. 111, 510-521. doi: 10.1111/j.14714159.2009.06335.x

Carlson, S. E., Rhodes, P. G., and Ferguson, M. G. (1986). Docosahexaenoic acid status of preterm infants at birth and following feeding with human milk or formula. Am. J. Clin. Nutr. 44, 798-804.

Carlson, S. E., Werkman, S. H., Rhodes, P. G., and Tolley, E. A. (1993). Visual-acuity development in healthy preterm infants: effect of marine-oil supplementation. Am. J. Clin. Nutr. 58, 35-42.

Caspi, A., Williams, B., Kim-Cohen, J., Craig, I. W., Milne, B. J., Poulton, R., et al. (2007). Moderation of breastfeeding effects on the IQ by genetic variation in fatty acid metabolism. Proc. Natl. Acad. Sci. 104, 18860-18865. doi: 10.1073/ pnas.0704292104

Catalan, J., Moriguchi, T., Slotnick, B., Murthy, M., Greiner, R. S., and Salem, N. Jr. (2002). Cognitive deficits in docosahexaenoic acid-deficient rats. Behav. Neurosci. 116, 1022-1031. doi: 10.1037/0735-7044.116.6.1022

Chalon, S. (2006). Omega-3 fatty acids and monoamine neurotransmission. Prostaglandins Leukot. Essent. Fatty Acids 75, 259-269. doi: 10.1016/j.plefa.2006.07.005

Champoux, M., Hibbeln, J. R., Shannon, C., Majchrzak, S., Suomi, S. J., Salem, N. Jr., et al. (2002). Fatty acid formula supplementation and neuromotor development in rhesus monkey neonates. Pediatr. Res. 51, 273-281. doi: 10.1203/00006450-200203000-00003

Clandinin, M. T., Chappell, J. E., Leong, S., Heim, T., Swyer, P. R., and Chance, G. W. (1980). Intrauterine fatty acid accretion rates in human brain: implications for fatty acid requirements. Early Hum. Dev. 4, 121-129. doi: 10.1016/03783782(80)90015-8

Clandinin, M. T., Van Aerde, J. E., Merkel, K. L., Harris, C. L., Springer, M. A., Hansen, J. W., et al. (2005). Growth and development of preterm infants fed infant formulas containing docosahexaenoic acid and arachidonic acid. J. Pediatr. 146, 461-468. doi: 10.1016/j.jpeds.2004.11.030

Cosatto, V. F., Else, P. L., and Meyer, B. J. (2010). Do pregnant women and those at risk of developing post-natal depression consume lower amounts of long chain omega-3 polyunsaturated fatty acids? Nutrients 2, 198-213. doi: 10.3390/nu2020198

Cunnane, S. C., Francescutti, V., Brenna, J. T., and Crawford, M. (2000). Breast-fed infants achieve a higher rate of brain and whole body docosahexaenoate accumulation than formula-fed infants not consuming dietary docosahexaenoate. Lipids 35, 105-111. doi: 10.1007/s11745-000-0501-6

Davis-Bruno, K., and Tassinari, M. S. (2011). Essential fatty acid supplementation of DHA and ARA and effects on neurodevelopment across animal species: a review of the literature. Birth Defects Res. B Dev. Reprod. Toxicol. 92, 240-250. doi: 10.1002/bdrb.20311

Decsi, T., and Kennedy, K. (2011). Sex-specific differences in essential fatty acid metabolism. Am. J. Clin. Nutr. 94(6 Suppl.), 1914-1919. doi: 10.3945/ajcn.110.000893

de Jager, E., Skouteris, H., Broadbent, J., Amir, L., and Mellor, K. (2013). Psychosocial correlates of exclusive breastfeeding: a systematic review. Midwifery 29, 506-518. doi: 10.1016/j.midw.2012.04.009

Der, G., Batty, G. D., and Deary, I. J. (2006). Effect of breast feeding on intelligence in children: prospective study, sibling pairs analysis, and meta-analysis. BMJ 333, 945. doi: 10.1136/bmj.38978.699583.55

de Urquiza, A. M., Liu, S., Sjoberg, M., Zetterstrom, R. H., Griffiths, W., Sjovall, J., et al. (2000). Docosahexaenoic acid, a ligand for the retinoid X receptor in mouse brain. Science 290, 2140-2144. doi: 10.1126/science.290.5499.2140

Dhar, B., Mowlah, G., and Kabir, D. M. (2003). Newborn anthropometry and its relationship with maternal factors. Bangladesh Med. Res. Counc. Bull. 29, 48-58.

Diau, G.-Y., Hsieh, A., Sarkadi-Nagy, E., Wijendran, V., Nathanielsz, P., and Brenna, J. T. (2005). The influence of long chain polyunsaturate supplementation on docosahexaenoic acid and arachidonic acid in baboon neonate central nervous system. BMC Med. 3:11. doi: 10.1186/1741-7015-3-11

Drane, D. L., and Logemann, J. A. (2000). A critical evaluation of the evidence on the association between type of infant feeding and cognitive development. Paediatr. Perinat. Epidemiol. 14, 349-356. doi: 10.1046/j.13653016.2000.00301.x

Drover, J. R., Hoffman, D. R., Castañeda, Y. S., Morale, S. E., Garfield, S., Wheaton, D. H., et al. (2011). Cognitive function in 18-month-old term infants of the DIAMOND study: a randomized, controlled clinical trial with multiple dietary levels of docosahexaenoic acid. Early Hum. Dev. 87, 223-230. doi: 10.1016/j.earlhumdev.2010.12.047
Dunstan, J. A., Simmer, K., Dixon, G., and Prescott, S. L. (2008). Cognitive assessment of children at age $2 \frac{1}{2} 2$ years after maternal fish oil supplementation in pregnancy: a randomised controlled trial. Arch. Dis. Child. Fetal Neonatal Ed. 93, 45-50. doi: 10.1136/adc.2006.099085

Eaton, S. B. (2000). Paleolithic vs. modern diets- selected pathophysiological implications. Eur. J. Nutr. 39, 67-70. doi: 10.1007/s003940070032

Extier, A., Langelier, B., Perruchot, M.-H., Guesnet, P., Van Veldhoven, P. P., Lavialle, M., et al. (2010). Gender affects liver desaturase expression in a rat model of n-3 fatty acid repletion. J. Nutr. Biochem. 21, 180-187. doi: 10.1016/j.jnutbio.2008.10.008

Farquharson, J., Jamieson, E. C., Abbasi, K. A., Patrick, W. J., Logan, R. W., and Cockburn, F. (1995). Effect of diet on the fatty acid composition of the major phospholipids of infant cerebral cortex. Arch. Dis. Child. 72, 198-203. doi: 10.1136/adc.72.3.198

Fedorova, I., and Salem, N. Jr. (2006). Omega-3 fatty acids and rodent behavior. Prostaglandins Leukot. Essent. Fatty Acids 75, 271-289. doi: 10.1016/j.plefa.2006.07.006

Fewtrell, M. S., Abbott, R. A., Kennedy, K., Singhal, A., Morley, R., Caine, E., et al. (2004). Randomized, double-blind trial of long-chain polyunsaturated fatty acid supplementation with fish oil and borage oil in preterm infants. J. Pediatr. 144, 471-479. doi: 10.1016/j.jpeds.2004.01.034

Fewtrell, M. S., Morley, R., Abbott, R. A., Singhal, A., Isaacs, E. B., Stephenson, T., et al. (2002). Double-blind, randomized trial of long-chain polyunsaturated fatty acid supplementation in formula fed to preterm infants. Pediatrics 110 , 73-82. doi: 10.1542/peds.110.1.73

Gale, C. R., Robinson, S. M., Godfrey, K. M., Law, C. M., Schlotz, W., and O'Callaghan, F. J. (2008). Oily fish intake during pregnancy-association with lower hyperactivity but not with higher full-scale IQ in offspring. J. Child Psychol. Psychiatry 49, 1061-1068. doi: 10.1111/j.1469-7610.2008.01908.x

Gibson, R. A., and Makrides, M. (1998). The role of long chain polyunsaturated fatty acids (LCPUFA) in neonatal nutrition. Acta Paediatr. 87, 1017-1022. doi: $10.1080 / 080352598750031301$

Gibson, R. A., Neumann, M. A., and Makrides, M. (1997). Effect of increasing breast milk docosahexaenoic acid on plasma and erythrocyte phospholipid fatty acids and neural indices of exclusively breast fed infants. Eur. J. Clin. Nutr. 51, 578. doi: 10.1038/sj.ejcn. 1600446

Gillingham, L. G., Harding, S. V., Rideout, T. C., Yurkova, N., Cunnane, S. C., Eck, P. K., et al. (2013). Dietary oils and FADS1-FADS2 genetic variants modulate [13C] $\alpha$-linolenic acid metabolism and plasma fatty acid composition. Am. J. Clin. Nutr. 97, 195-207. doi: 10.3945/ajcn.112.043117

Giltay, E. J., Gooren, L. J. G., Toorians, A. W. F. T., Katan, M. B., and Zock, P. L. (2004). Docosahexaenoic acid concentrations are higher in women than in men because of estrogenic effects. Am. J. Clin. Nutr. 80, 1167-1174.

Glaser, C., Lattka, E., Rzehak, P., Steer, C., and Koletzko, B. (2011). Genetic variation in polyunsaturated fatty acid metabolism and its potential relevance for human development and health. Matern. Child Nutr. 7, 27-40. doi: 10.1111/j.1740-8709.2011.00319.x

Gould, J. F., Smithers, L. G., and Makrides, M. (2013). The effect of maternal omega-3 (n-3) LCPUFA supplementation during pregnancy on early childhood cognitive and visual development: a systematic review and metaanalysis of randomized controlled trials. Am. J. Clin. Nutr. 97, 531-544. doi: 10.3945/ajcn.112.045781

Guesnet, P., and Alessandri, J. M. (2011). Docosahexaenoic acid (DHA) and the developing central nervous system (CNS) - Implications for dietary recommendations. Biochimie 93, 7-12. doi: 10.1016/j.biochi.2010.05.005

Haggarty, P. (2002). Placental regulation of fatty acid delivery and its effect on fetal growth-a review. Placenta S23, 28-38. doi: 10.1053/plac.2002.0791

Heimann, M., Strid, K., Smith, L., Tjus, T., Erik Ulvund, S., and Meltzoff, A. N. (2006). Exploring the relation between memory, gestural communication, and the emergence of language in infancy: a longitudinal study. Infant Child Dev. 15, 233-249. doi: 10.1002/icd.462

Helland, I. B., Smith, L., Blomén, B., Saarem, K., Saugstad, O. D., and Drevon, C. A. (2008). Effect of supplementing pregnant and lactating mothers with n-3 verylong-chain fatty acids on children's IQ and body mass index at 7 years of age. Pediatrics 122, 472-479. doi: 10.1542/peds.2007-2762

Helland, I. B., Smith, L., Saarem, K., Saugstad, O. D., and Drevon, C. A. (2003). Maternal supplementation with very-long-chain n-3 fatty acids during pregnancy and lactation augments children's IQ at 4 years of age. Pediatrics 111, 39-44. doi: 10.1542/peds.111.1.e39 
Henriksen, C., Haugholt, K., Lindgren, M., Aurvåg, A. K., Rønnestad, A., Grønn, M., et al. (2008). Improved cognitive development among preterm infants attributable to early supplementation of human milk with docosahexaenoic acid and arachidonic acid. Pediatrics 121, 1137-1145. doi: 10.1542/peds. 2007-1511

Hibbeln, J. R., Davis, J. M., Steer, C., Emmett, P. M., Rogers, I., Williams, C., et al. (2007). Maternal seafood consumption in pregnancy and neurodevelopmental outcomes in childhood (ALSPAC study): an observational cohort study. Lancet 369, 578-585. doi: 10.1016/S0140-6736(07)60277-3

Hoffman, D. R., Boettcher, J. A., and Diersen-Schade, D. A. (2009). Toward optimizing vision and cognition in term infants by dietary docosahexaenoic and arachidonic acid supplementation: a review of randomized controlled trials. Prostaglandins Leukot. Essent. Fatty Acids 81, 151-158. doi: 10.1016/j.plefa.2009.05.003

Horrocks, L. A., and Farooqui, A. A. (2004). Docosahexaenoic acid in the diet: its importance in maintenance and restoration of neural membrane function. Prostaglandins Leukot. Essent. Fatty Acids 70, 361-372. doi: 10.1016/j.plefa.2003.12.011

Howe, P., Meyer, B., Record, S., and Baghurst, K. (2006). Dietary intake of longchain n-3 polyunsaturated fatty acids: contribution of meat sources. Nutrition 22, 47-53. doi: 10.1016/j.nut.2005.05.009

Ikemoto, A., Ohishi, M., Sato, Y., Hata, N., Misawa, Y., Fujii, Y., et al. (2001). Reversibility of n-3 fatty acid deficiency-induced alterations of learning behavior in the rat: level of n-6 fatty acids as another critical factor. J. Lipid Res. 42, 1655-1663.

Innis, S. M. (2003). Perinatal biochemistry and physiology of long-chain polyunsaturated fatty acids. J. Pediatr. 143, 1-8. doi: 10.1067/S0022-3476(03)00396-2

Innis, S. M. (2005). Essential fatty acid transfer and fetal development. Placenta 26, 70-75. doi: 10.1016/j.placenta.2005.01.005

Innis, S. M. (2007). Dietary (n-3) fatty acids and brain development. J. Nutr. 137, $855-859$.

Innis, S. M. (2008). Dietary omega 3 fatty acids and the developing brain. Brain Res. 1237, 35-43. doi: 10.1016/j.brainres.2008.08.078

Innis, S. M., Gilley, J., and Werker, J. (2001). Are human milk long-chain polyunsaturated fatty acids related to visual and neural development in breast-fed term infants? J. Pediatr. 139, 532-538. doi: 10.1067/mpd.2001.118429

Jacobson, J. L., Jacobson, S. W., Muckle, G., Kaplan-Estrin, M., Ayotte, P., and Dewailly, E. (2008). Beneficial effects of a polyunsaturated fatty acid on infant development: evidence from the inuit of arctic quebec. J. Pediatr. 152, 356-364. doi: 10.1016/j.jpeds.2007.07.008

Jain, A., Concato, J., and Leventhal, J. M. (2002). How good is the evidence linking breastfeeding and intelligence? Pediatrics 109, 1044-1053. doi: 10.1542/peds.109.6.1044

Jensen, C. L., Voigt, R. G., Prager, T. C., Zou, Y. L., Fraley, J. K., Rozelle, J. C., et al. (2005). Effects of maternal docosahexaenoic acid intake on visual function and neurodevelopment in breastfed term infants. Am. J. Clin. Nutr. 82, 125-132.

Jørgensen, M. H., Hernell, O., Hughes, E. L., and Michaelsen, K. F. (2001). Is there a relation between docosahexaenoic acid concentration in mothers' milk and visual development in term infants? J. Pediatr. Gastroenterol. Nutr. 32, 293-296. doi: 10.1097/00005176-200103000-00011

Judge, M. P., Harel, O., and Lammi-Keefe, C. J. (2007). Maternal consumption of a docosahexaenoic acid-containing functional food during pregnancy: benefit for infant performance on problem-solving but not on recognition memory tasks at age 9 mo. Am. J. Clin. Nutr. 85, 1572-1577.

Karim, E., and Mascie-Taylor, C. G. N. (1997). The association between birthweight, sociodemographic variables and maternal anthropometry in an urban sample from Dhaka, Bangladesh. Ann. Hum. Biol. 24, 387-401. doi: 10.1080/03014469700005152

Karr, J. E., Alexander, J. E., and Winningham, R. G. (2011). Omega-3 polyunsaturated fatty acids and cognition throughout the lifespan: a review. Nutr. Neurosci. 14, 216-225. doi: 10.1179/1476830511Y.0000000012

Kitajka, K., Sinclair, A. J., Weisinger, R. S., Weisinger, H. S., Mathai, M., Jayasooriya, A. P., et al. (2004). Effects of dietary omega-3 polyunsaturated fatty acids on brain gene expression. Proc. Natl. Acad. Sci. U.S.A. 101, 10931-10936. doi: 10.1073/pnas.0402342101

Koletzko, B., Baker, S., Cleghorn, G., Neto, U. F., Gopalan, S. F., Hernell, O., et al. (2005). Global standard for the composition of infant formula: recommendations of an ESPGHAN coordinated international expert group. J. Pediatr. Gastroenterol. Nutr. 41, 584-599. doi: 10.1097/01.mpg.0000187817.38836.42
Koletzko, B., Lattka, E., Zeilinger, S., Illig, T., and Steer, C. (2011). Genetic variants of the fatty acid desaturase gene cluster predict amounts of red blood cell docosahexaenoic and other polyunsaturated fatty acids in pregnant women: findings from the Avon longitudinal study of parents and children. Am. J. Clin. Nutr. 93, 211-219. doi: 10.3945/ajcn.110.006189

Koletzko, B., Lien, E., Agostoni, C., Boehles, H., Campoy, C., Cetin, I., et al. (2008). The roles of long-chain polyunsaturated fatty acids in pregnancy, lactation and infancy: review of current knowledge and consensus recommendations. J. Perinat. Med. 36, 5-14. doi: 10.1515/JPM.2008.001

Koletzko, B., Schmidt, E., Bremer, H. J., Haug, M., and Harzer, G. (1989). Effects of dietary long-chain polyunsaturated fatty acids on the essential fatty acid status of premature infants. Eur. J. Pediatr. 148, 669-675. doi: 10.1007/ BF00441531

Kramer, M. S., Aboud, F., Mironova, E., Vanilovich, I., Platt, R. W., Matush, L., et al. (2008). Breastfeeding and child cognitive development: new evidence from a large randomized trial. Arch. Gen. Psychiatry 65, 578-584. doi: 10.1001/archpsyc.65.5.578

Kramer, M. S., and Kakuma, R. (2001). The Optimal Duration of Exclusive Breastfeeding: A Systematic Review. Geneva: World Health Organization.

Kris-Etherton, P. M., Taylor, D. S., Yu-Poth, S., Huth, P., Moriarty, K., Fishell, V., et al. (2000). Polyunsaturated fatty acids in the food chain in the United States. Am. J. Clin. Nutr. 71, 179-188.

Lapillonne, A., Groh, W. S., Lozano Gonzalez, C. H., and Uauy, R. (2013). Lipid needs of preterm infants: updated recommendations. J. Pediatr. 162(Suppl. 3), 37-47. doi: 10.1016/j.jpeds.2012.11.052

Lapillonne, A., Picaud, J. C., Chirouze, V., Goudable, J., Reygrobellet, B., Claris, O., et al. (2000). The use of low-EPA fish oil for long-chain polyunsaturated fatty acid supplementation of preterm infants. Pediatr. Res. 48, 835-841. doi: 10.1203/00006450-200012000-00022

Larqué, E., Gil-Sánchez, A., Prieto-Sánchez, M. T., and Koletzko, B. (2012). Omega 3 fatty acids, gestation and pregnancy outcomes. Br. J. Nutr. 107, 77-84. doi: 10.1017/S0007114512001481

Lattka, E., Koletzko, B., Zeilinger, S., Hibbeln, J. R., Klopp, N., Ring, S. M., et al. (2013). Umbilical cord PUFA are determined by maternal and child fatty acid desaturase (FADS) genetic variants in the Avon longitudinal study of parents and children (ALSPAC). Br. J. Nutr. 109, 1196-1210. doi: 10.1017/ S0007114512003108

Lauritzen, L., Jorgensen, M. H., Olsen, S. F., Straarup, E. M., and Michaelsen, K. F. (2005). Maternal fish oil supplementation in lactation: effect on developmental outcome in breast-fed infants. Reprod. Nutr. Dev. 45, 535-548. doi: 10.1051/rnd:2005044

Lim, S.-Y., Hoshiba, J., and Salem, N. Jr. (2005). An extraordinary degree of structural specificity is required in neural phospholipids for optimal brain function: n-6 docosapentaenoic acid substitution for docosahexaenoic acid leads to a loss in spatial task performance. J. Neurochem. 95, 848-857. doi: 10.1111/j.1471-4159.2005.03427.x

Lo, A., Sienna, J., Mamak, E., Djokanovic, N., Westall, C., and Koren, G. (2012). The effects of maternal supplementation of polyunsaturated fatty acids on visual, neurobehavioural, and developmental outcomes of the child: a systematic review of the randomized trials. Obstet. Gynecol. Int. 2012:9 doi: 10.1155/ 2012/591531

Lucas, A., Stafford, M., Morley, R., Abbott, R., Stephenson, T., MacFadyen, U., et al. (1999). Efficacy and safety of long-chain polyunsaturated fatty acid supplementation of infant-formula milk: a randomised trial. Lancet 354, 1948-1954. doi: 10.1016/S0140-6736(99)02314-4

Luchtman, D. W., and Song, C. (2013). Cognitive enhancement by omega-3 fatty acids from child-hood to old age: findings from animal and clinical studies. Neuropharmacology 64, 550-565. doi: 10.1016/j.neuropharm.2012.07.019

Makrides, M., Gibson, R. A., McPhee, A. J., Yell, L., Quinlivan, J., and Ryan, P. (2011a). Effect of DHA supplementation during pregnancy on maternal depression and neurodevelopment of young children: a randomized controlled trial. Obstet. Gynecol. Surv. 66, 79. doi: 10.1097/OGX.0b013e3182168486

Makrides, M., Collins, C. T., and Gibson, R. A. (2011b). Impact of fatty acid status on growth and neurobehavioural development in humans. Matern. Child Nutr. 7, 80-88. doi: 10.1111/j.1740-8709.2011.00304.x

Makrides, M., Gibson, R. A., McPhee, A. J., Collins, C. T., Davis, P. G., Doyle, L. W., et al. (2009). Neurodevelopmental outcomes of preterm infants fed high-dose docosahexaenoic acid. J. Am. Med. Assoc. 301, 175-182. doi: 10.1001/jama.2008.945 
Makrides, M., Neumann, M. A., Byard, R. W., Simmer, K., and Gibson, R. A. (1994). Fatty acid composition of brain, retina, and erythrocytes in breast- and formula-fed infants. Am. J. Clin. Nutr. 60, 189-194.

Makrides, M., Neumann, M. A., Simmer, K., and Gibson, R. A. (2000). A critical appraisal of the role of dietary long-chain polyunsaturated fatty acids on neural indices of term infants: a randomized, controlled trial. Pediatrics 105, 32-38. doi: $10.1542 /$ peds.105.1.32

Makrides, M., Simmer, K., Neumann, M., and Gibson, R. A. (1995). Changes in the polyunsaturated fatty acids of breast milk from mothers of full-term infants over 30 wk of lactation. Am. J. Clin. Nutr. 61, 1231-1233.

Martinez, M., Conde, C., and Ballabriga, A. (1974). Some chemical aspects of human brain development. II. Phosphoglyceride fatty acids. Pediatr. Res. 8, 93-102. doi: 10.1203/00006450-197402000-00005

Martinez, M., and Mougan, I. (1998). Fatty acid composition of human brain phospholipids during normal development. J. Neurochem. 71, 2528-2533. doi: 10.1046/j.1471-4159.1998.71062528.x

McCann, J. C., and Ames, B. N. (2005). Is docosahexaenoic acid, an n-3 long-chain polyunsaturated fatty acid, required for development of normal brain function? An overview of evidence from cognitive and behavioral tests in humans and animals. Am. J. Clin. Nutr. 82, 281-295.

McCann, J. C., and Ames, B. N. (eds.). (2010). Evidence Required for Causal Inferences About Effects of Micronutrient Deficiencies During Development on Brain Health. Vol. 26. Boca Raton, FL: CPR Press.

McManus, A., Merga, M., and Newton, W. (2011). Omega-3 fatty acids. What consumers need to know. Appetite 57, 80-83. doi: 10.1016/j.appet.2011.03.015

McNamara, R. K., and Carlson, S. E. (2006). Role of omega-3 fatty acids in brain development and function: potential implications for the pathogenesis and prevention of psychopathology. Prostaglandins Leukot. Essent. Fatty Acids 75, 329-349. doi: 10.1016/j.plefa.2006.07.010

Meldrum, S. J., D’Vaz, N., Simmer, K., Dunstan, J. A., Hird, K., and Prescott, S. L. (2012). Effects of high-dose fish oil supplementation during early infancy on neurodevelopment and language: a randomised controlled trial. Br. J. Nutr. 108, 1443-1454. doi: 10.1017/S0007114511006878

Meldrum, S. J., Smith, M. A., Prescott, S. L., Hird, K., and Simmer, K. (2011). Achieving definitive results in term infant LCPUFA supplementation trials: factors for consideration. Nutr. Rev. 69, 205-214. doi: 10.1111/j.17534887.2011.00381.x

Mendez, M. A., Torrent, M., Julvez, J., Ribas-Fitó, N., Kogevinas, M., and Sunyer, J. (2009). Maternal fish and other seafood intakes during pregnancy and child neurodevelopment at age 4 years. Public Health Nutr. 12, 1702-1710. doi: $10.1017 /$ S1368980008003947

Meyer, B. J. (2011). Are we consuming enough long chain omega-3 polyunsaturated fatty acids for optimal health? Prostaglandins Leukot. Essent. Fatty Acids 85, 275-280. doi: 10.1016/j.plefa.2011.04.010

Molloy, C., Doyle, L. W., Makrides, M., and Anderson, P. J. (2012). Docosahexaenoic acid and visual functioning in preterm infants: a review. Neuropsychol. Rev. 22, 425-437. doi: 10.1007/s11065-012-9216-Z

Moltó-Puigmartí, C., Plat, J., Mensink, R. P., Müller, A., Jansen, E., Zeegers, M. P., et al. (2010). FADS1 FADS2 gene variants modify the association between fish intake and the docosahexaenoic acid proportions in human milk. Am. J. Clin. Nutr. 91, 1368-1376. doi: 10.3945/ajcn.2009.28789

Moriguchi, T., Greiner, R. S., and Salem, N. Jr. (2000). Behavioral deficits associated with dietary induction of decreased brain docosahexaenoic acid concentration. J. Neurochem. 75, 2563-2573. doi: 10.1046/j.1471-4159.2000.0752563.x

Morley, R., Cole, T. J., Powell, R., and Lucas, A. (1988). Mother's choice to provide breast milk and developmental outcome. Arch. Dis. Child. 63, 1382-1385. doi: 10.1136/adc.63.11.1382

Nakamura, M. T., and Nara, T. Y. (2004). Structure, function, and dietary regulation of delta 6, delta 5, and delta 9 desaturases. Annu. Rev. Nutr. 24, 345-376. doi: 10.1146/annurev.nutr.24.121803.063211

Neuringer, M., Connor, W. E., Lin, D. S., Barstad, L., and Luck, S. (1986). Biochemical and functional effects of prenatal and postnatal omega 3 fatty acid deficiency on retina and brain in rhesus monkeys. Proc. Natl. Acad. Sci. U.S.A. 83, 4021-4025. doi: 10.1073/pnas.83.11.4021

Nyaradi, A., Li, J., Hickling, S., Foster, J. K., and Oddy, W. H. (2013). The role of nutrition in children's neurocognitive development, from pregnancy through childhood. Front. Hum. Neurosci. 7:97. doi: 10.3389/fnhum.2013.00097

O'Connor, D. L., Hall, R., Adamkin, D., Auestad, N., Castillo, M., Connor, W. E., et al. (2001). Growth and development in preterm infants fed long-chain polyunsaturated fatty acids: a prospective, randomized controlled trial. Pediatrics 108, 359-371. doi: 10.1542/peds.108.2.359

Oddy, W. H., Kendall, G. E., Blair, E., De Klerk, N. H., Stanley, F. J., Landau, L. I., et al. (2003). Breast feeding and cognitive development in childhood: a prospective birth cohort study. Paediatr. Perinat. Epidemiol. 17, 81-90. doi: 10.1046/j.1365-3016.2003.00464.x

Oddy, W. H., Li, J., Whitehouse, A. J. O., Zubrick, S. R., and Malacova, E. (2011). Breastfeeding duration and academic achievement at 10 years. Pediatrics 127, 137-145. doi: 10.1542/peds.2009-3489

Oken, E., Radesky, J. S., Wright, R. O., Bellinger, D. C., Amarasiriwardena, C. J., Kleinman, K. P., et al. (2008). Maternal fish intake during pregnancy, blood mercury levels, and child cognition at age 3 years in a US cohort. Am. J. Epidemiol. 167, 1171-1181. doi: 10.1093/aje/kwn034

Oken, E., Wright, R. O., Kleinman, K. P., Bellinger, D., Amarasiriwardena, C. J., Hu, H., et al. (2005). Maternal fish consumption, hair mercury, and infant cognition in a US cohort. Environ. Health Perspect. 113, 1376. doi: 10.1289/ehp.8041

Parletta, N., Milte, C. M., and Meyer, B. J. (2013). Nutritional modulation of cognitive function and mental health. J. Nutr. Biochem. 24, 725-743. doi: 10.1016/j.jnutbio.2013.01.002

Perricone, G., and Morales, M. R. (2011). The temperament of preterm infant in preschool age. Ital. J. Pediatr. 37, 1-7. doi: 10.1186/1824-7288-37-4

Plourde, M., and Cunnane, S. C. (2007). Extremely limited synthesis of long chain polyunsaturates in adults: implications for their dietary essentiality and use as supplements. Appl. Physiol. Nutr. Metab. 32, 619-634. doi: 10.1139/H07-034

Qawasmi, A., Landeros-Weisenberger, A., Leckman, J. F., and Bloch, M. H. (2012). Meta-analysis of long-chain polyunsaturated fatty acid supplementation of formula and infant cognition. Pediatrics 129, 1141-1149. doi: 10.1542/peds.20112127

Rogers, L. K., Valentine, C. J., and Keim, S. A. (2013). DHA supplementation: current implications in pregnancy and childhood. Pharmacol. Res. 70, 13-19. doi: 10.1016/j.phrs.2012.12.003

Rolls, E. T. (2008). “The primate hippocampus and episodic memory," in Handbook of Behavioral Neuroscience, Vol. 18, eds E. Dere, A. Easton, L. Nadel, and P. Joseph (Oxford: Elsevier), 417-626 doi: 10.1016/SI569-7339(08)00223-3

Romijn, H. J., Hofman, M. A., and Gramsbergen, A. (1991). At what age is the developing cerebral cortex of the rat comparable to that of the fullterm newborn human baby? Early Hum. Dev. 26, 61-67. doi: 10.1016/03783782(91)90044-4

Russo, G. L. (2009). Dietary n-6 and n-3 polyunsaturated fatty acids: from biochemistry to clinical implications in cardiovascular prevention. Biochem. Pharmacol. 77, 937-946. doi: 10.1016/j.bcp.2008.10.020

Rzehak, P., Heinrich, J., Klopp, N., Schaeffer, L., Hoff, S., Wolfram, G., et al. (2009). Evidence for an association between genetic variants of the fatty acid desaturase 1 fatty acid desaturase 2 (FADS1 FADS2) gene cluster and the fatty acid composition of erythrocyte membranes. Br. J. Nutr. 101, 20-26. doi: 10.1017/S0007114508992564

SanGiovanni, J. P., Berkey, C. S., Dwyer, J. T., and Colditz, G. A. (2000). Dietary essential fatty acids, long-chain polyunsaturated fatty acids, and visual resolution acuity in healthy fullterm infants: a systematic review. Early Hum. Dev. 57, 165-188. doi: 10.1016/S0378-3782(00)00050-5

Schaeffer, L., Gohlke, H., Muller, M., Heid, I. M., Palmer, L. J., Kompauer, I., et al. (2006). Common genetic variants of the FADS1 FADS2 gene cluster and their reconstructed haplotypes are associated with the fatty acid composition in phospholipids. Hum. Mol. Genet. 15, 1745-1756. doi: 10.1093/hmg/ ddl117

Schulzke, S. M., Patole, S. K., and Simmer, K. (2011). Longchain polyunsaturated fatty acid supplementation in preterm infants. Cochrane Database Syst. Rev. doi: 10.1002/14651858.CD000375.pub4

Scott, D. T., Janowsky, J. S., Carroll, R. E., Taylor, J. A., Auestad, N., and Montalto, M. B. (1998). Formula supplementation with long-chain polyunsaturated fatty acids: are there developmental benefits? Pediatrics 102, E59. doi: 10.1542/peds.102.5.e59

Sheaff, G. R. C., Moriguchi, T., Hutton, A., Slotnick, B. M., and Salem, N. Jr. (1999). Rats with low levels of brain docosahexaenoic acid show impaired performance in olfactory-based and spatial learning tasks. Lipids 34, 239-243. doi: 10.1007/BF02562305

Simmer, K. (2001). Longchain polyunsaturated fatty acid supplementation in infants born at term. Cochrane Database Syst. Rev. doi: 10.1002/14651858. CD000376 
Simmer, K., Patole, S. K., and Rao, S. C. (2008). Longchain polyunsaturated fatty acid supplementation in infants born at term. Cochrane Database Syst. Rev. doi: 10.1002/14651858.CD000375.pub3

Simmer, K., Patole, S. K., and Rao, S. C. (2011). Longchain polyunsaturated fatty acid supplementation in infants born at term. Cochrane Database Syst. Rev. doi: 10.1002/14651858.CD000376.pub3

Simopoulos, A. P. (2001a). Evolutionary aspects of diet, essential fatty acids and cardiovascular disease. Eur. Heart J. Suppl. 3(Suppl. D), 8-21. doi: 10.1016/S1520765X(01)90113-0

Simopoulos, A. P. (2001b). n-3 fatty acids and human health: defining strategies for public policy. Lipids 36, 83-89. doi: 10.1007/s11745-001-0687-7

Smithers, L. G., Gibson, R. A., McPhee, A., and Makrides, M. (2008a). Effect of long-chain polyunsaturated fatty acid supplementation of preterm infants on disease risk and neurodevelopment: a systematic review of randomized controlled trials. Am. J. Clin. Nutr. 87, 912-920.

Smithers, L. G., Gibson, R. A., McPhee, A., and Makrides, M. (2008b). Higher dose of docosahexaenoic acid in the neonatal period improves visual acuity of preterm infants: results of a randomized controlled trial. Am. J. Clin. Nutr. 88, 1049-1056.

Stewart, L. A., and Parmar, M. K. B. (1993). Meta-analysis of the literature or of individual patient data: is there a difference? Lancet 341, 418-422. doi: 10.1016/0140-6736(93)93004-K

Szajewska, H. (2011). The role of meta-analysis in the evaluation of the effects of early nutrition on mental and motor development in children. Am. J. Clin. Nutr. 94, 1889-1895. doi: 10.3945/ajcn.110.000653

Tofail, F., Kabir, I., Hamadani, J. D., Chowdhury, F., Yesmin, S., Mehreen, F., et al. (2006). Supplementation of fish-oil and soy-oil during pregnancy and psychomotor development of infants. J. Health Popul. Nutr. 24, 48-56.

Uauy, R., Mena, P., Wegher, B., Nieto, S., and Salem, N. Jr. (2000). Long chain polyunsaturated fatty acid formation in neonates: effect of gestational age and intrauterine growth. Pediatr. Res. 47, 127. doi: 10.1203/00006450-20000100000022
Van Elswyk, M., and Kuratko, C. (2009). Achieving adequate DHA in maternal and infant diets. J. Am. Diet. Assoc. 109, 403-404. doi: 10.1016/j.jada.2009.01.004

Xie, L., and Innis, S. M. (2008). Genetic variants of the FADS1 FADS2 gene cluster are associated with altered (n-6) and (n-3) essential fatty acids in plasma and erythrocyte phospholipids in women during pregnancy and in breast milk during lactation. J. Nutr. 138, 2222-2228. doi: 10.3945/jn.108.096156

Youdim, K. A., Martin, A., and Joseph, J. A. (2000). Essential fatty acids and the brain: possible health implications. Int. J. Dev. Neurosci. 18, 383-399. doi: 10.1016/S0736-5748(00)00013-7

Zimmer, L., Vancassel, S., Cantagrel, S., Breton, P., Delamanche, S., Guilloteau, D., et al. (2002). The dopamine mesocorticolimbic pathway is affected by deficiency in n-3 polyunsaturated fatty acids. Am. J. Clin. Nutr.75, 662-667.

Conflict of Interest Statement: The authors declare that the research was conducted in the absence of any commercial or financial relationships that could be construed as a potential conflict of interest.

Received: 15 April 2013; accepted: 27 October 2013; published online: 20 November 2013.

Citation: Heaton AE, Meldrum SJ, Foster JK, Prescott SL and Simmer K (2013)

Does docosahexaenoic acid supplementation in term infants enhance neurocognitive functioning in infancy? Front. Hum. Neurosci. 7:774. doi: 10.3389/fnhum.2013.00774 This article was submitted to the journal Frontiers in Human Neuroscience.

Copyright (c) 2013 Heaton, Meldrum, Foster, Prescott and Simmer. This is an open-access article distributed under the terms of the Creative Commons Attribution License (CC BY). The use, distribution or reproduction in other forums is permitted, provided the original author(s) or licensor are credited and that the original publication in this journal is cited, in accordance with accepted academic practice. No use, distribution or reproduction is permitted which does not comply with these terms. 